\title{
Occupational associations of testicular cancer in south east England
}

\author{
A J SWERDLOW*,' R G SKEET \\ From the University of Glasgow Department of Community Medicine, ${ }^{1}$ Ruchill Hospital, Glasgow G20 9 NB, \\ and The Thames Cancer Registry, ${ }^{2}$ Belmont, Sutton, Surrey SM2 SPY, UK
}

\begin{abstract}
The relation of occupation to the risk of testicular cancer was investigated in a casecontrol study using data from the files of the South Thames Cancer Registry. Risks by age and histology subdivisions of the tumour were investigated since there is epidemiological evidence of differences in aetiology between these subdivisions but no previous systematic study of occupational risks by age and histology. Analyses were conducted comparing 1605 cases of testicular cancer incident in the region during 1958-77 with 7187 controls selected from other cancers incident in men in the region during the same period. The greatest risks of testicular cancer overall were for administrators and managers, sales workers, professional and allied workers, electrical workers, and clerical workers; these occupations were generally also at high risk of subdivisions of the tumour age and histology. Risk of testicular cancer overall and in each age and histology subgroup was greater in men of high than of low occupation based social class. Occupations with high risk of testicular cancer for their social class are of particular interest for further investigation of possible occupational risk factors; occupations with this characteristic for testicular cancer overall or in subdivisions in the present and some previous data are farmers, electrical workers, and paper and printing workers.
\end{abstract}

The incidence of testicular cancer in young men is increasing in many "developed" populations ${ }^{1-3}$ but the reasons for this increase remain unknown. Several data sets show a raised risk of the tumour in professional and administrative workers, ${ }^{24-9}$ farmers or subgroups of farmers, ${ }^{47-14}$ and military men, ${ }^{15}$ and there have been unconfirmed reports of a raised risk in various other groups. ${ }^{61316}$ No specific occupational carcinogens have been identified, however, and it is not clear to what extent those occupational associations which have been found repeatedly are due to possible occupational exposures or to possible lifestyle or other associations of occupation. There is evidence that testicular cancer has different epidemiological characteristics in young men and in older men, and that testicular cancers at these different ages should be regarded as different aetiological entities. ${ }^{1718}$ No studies of occupation and testicular cancer have subdivided their data by age in this manner, however. There is also evidence that for some variables risk of

*Present address: Office of Population Censuses and Surveys, St Catherines House, 10 Kingsway, London WC2B 6JP. testicular cancer differs by histology, ${ }^{19}$ but few data have been published comparing risks by histology and then for only two occupations. ${ }^{420}$ The present study used 20 years of data from a population based cancer registry to investigate the relation of occupation and occupation based social class to risk of testicular cancer, both overall and subdivided by age and by histology.

\section{Materials and methods}

The South Thames Cancer Registry* was a population based registry covering the population of the South West and South East Thames Health Regions as well as, before 1973, the Wessex Region. Completeness and accuracy of registration appear generally to have been high, ${ }^{21}{ }^{22}$ although some variations in quality have probably occurred in collecting data over a long period from a population of over six million. The registry collected data on occupation and occupation based social class of patients with cancer, coded according to the Registrar General's classifications ${ }^{23}$ : the 1960 classification for data from 1958 to 1969 and

*Now superseded by the Thames Cancer Registry. 
the 1970 classification for data from 1970 to 1977 . The differences between these two classifications were minor for occupation order (the only substantial relevant change was the transfer of the occupation unit boiler scalers from order XVII to order XVIII) and for social class ${ }^{23}$ and were therefore ignored in the present analyses. Certain occupation orders (II, III, IV, V, IX, $\mathrm{X}, \mathrm{XI}, \mathrm{XIV}$, and XVII) occurred rarely among the study subjects and were therefore combined in the analyses to form a single group designated below as "other stated occupations."

Denominator data to calculate rates for the variables of interest were not available. Case-control analyses were therefore conducted to assess the relation of these variables to risk of testicular cancer. The case-control approach was preferred to a proportional registration ratio (PRR) analysis because unlike PRR analysis it is independent of the size of the auxiliary causes - that is, non-testicular cancer-domain, ${ }^{24}$ and because it avoids the bias that occurs in PRRs calculated using all occupied men or all men as the comparison, that the occupation of interest influences both the observed and the expected values, and this influence is greater for common than for rare occupations or classes - that is to say, PRRs for common occupations and classes are biased towards 100 more greatly than are PRRs for rare ones.

Data on all malignancies classified in the International Classification of Diseases (ICD) ${ }^{25}$ as primary testicular cancer (ICD7 178 from 1958 to 1967; ICD8 186 from 1968 to 1977) registered in residents of the South Thames Cancer Registry area during 1958-77 were extracted from the computer files of the registry. The controls for the study were selected in the following manner from other cancers in men in the same years of the registry files: a file was created containing all cancers in men aged 15-19, a 50\% random sample of cancers in men aged $20-44$, and a $10 \%$ random sample of cancers in men aged $45-74$. From this file two types of exclusion were made to leave the controls for the study. Firstly, men with cancers of the testis, other cancers of the genital system, and cancers of unspecified primary site were excluded. Secondly, for each three digit ICD site which constituted more than $15 \%$ of the controls in any five year age group, reductions in the number of cancers of that site included in the control group were made by random sampling such that after the reductions in each age group no individual cancer site constituted more than $15 \%$ of the controls. The intention of this reduction was to ensure that in each age group cases were compared with a wide range of control diagnoses rather than mainly with one or two control diagnoses (such as Hodgkin's disease in young adults or lung cancer in older adults).

The case and control groups thus constituted were analysed as an unmatched case-control study with stratification by age. ${ }^{26-28}$ The baseline group used for calculation of relative risks was the largest group ${ }^{28}$ : for occupational analyses this was XXV professional, technical workers, artists; for social class analyses it was social class III. This method of analysis was used to give relative risks for different occupations which may be compared directly with each other; it should be noted when examining the results, however, that it is the comparative magnitudes of the risks thus calculated that are of interest, but there is little importance in the absolute values of the relative risks compared with 1.0 and the relations of the confidence limits to 1.0 because the baseline group were not "unexposed" (there can be no consistent unexposed group in an investigation of the present type). Risks of testicular cancer were analysed for the age groups 1544 and $45-74$, as well as for age 15-74 overall. Risks age 65-74 were also examined separately to seek whether inclusion of these retired men in the above analyses would lead to bias; since this examination did not give evidence of bias (although based often on small numbers), risks age 65-74 have not been presented separately here.

\section{Results}

Altogether 2250 cases of testicular cancer were registered in residents of the South Thames Cancer Registry Region in 1958-77; their age and histology distribution is shown in the figure. Fifty four per cent of the 1911 tumours of known laterality were right sided (54\% of seminomas and $56 \%$ of teratomas; $59 \%$ age $15-24$ years decreasing to $50 \%$ age $45-54$ and around $50 \%$ thereafter) and under $1 \%$ were bilateral.

A total of 314000 cancers of sites other than the testis were registered in male residents of the region, 1958-77; 224000 of these were in men aged 15-74, of which 9834 were included in the control file for the study. The commonest cancer sites among the controls were bonchus $(7.5 \%$ of the controls), larynx $(6.6 \%)$, brain $(5.7 \%)$, urinary tract other than bladder $(5.4 \%)$, rectum $(5 \cdot 1 \%)$, oesophagus $(4 \cdot 6 \%)$, lymphosarcoma $(4 \cdot 6 \%)$, pancreas $(4 \cdot 1 \%)$, and cutaneous melanoma (3.9\%). Occupation was known for $1605(75.2 \%)$ cases and $7187(73.1 \%)$ controls and social class for $1533(71 \cdot 8 \%)$ cases and $6855(69 \cdot 7 \%)$ controls. The percentage known did not vary greatly between age and histology subgroups of the cases, although it was slightly higher age 45-74 than 15-44 and for teratoma than seminoma.

Table 1 shows the relative risks of testicular cancer by occupation order. For testicular cancer overall the greatest risks were for XXIV administrators and managers, XXII sales workers, XXV professional, technical workers, and artists, VI electrical and elec- 

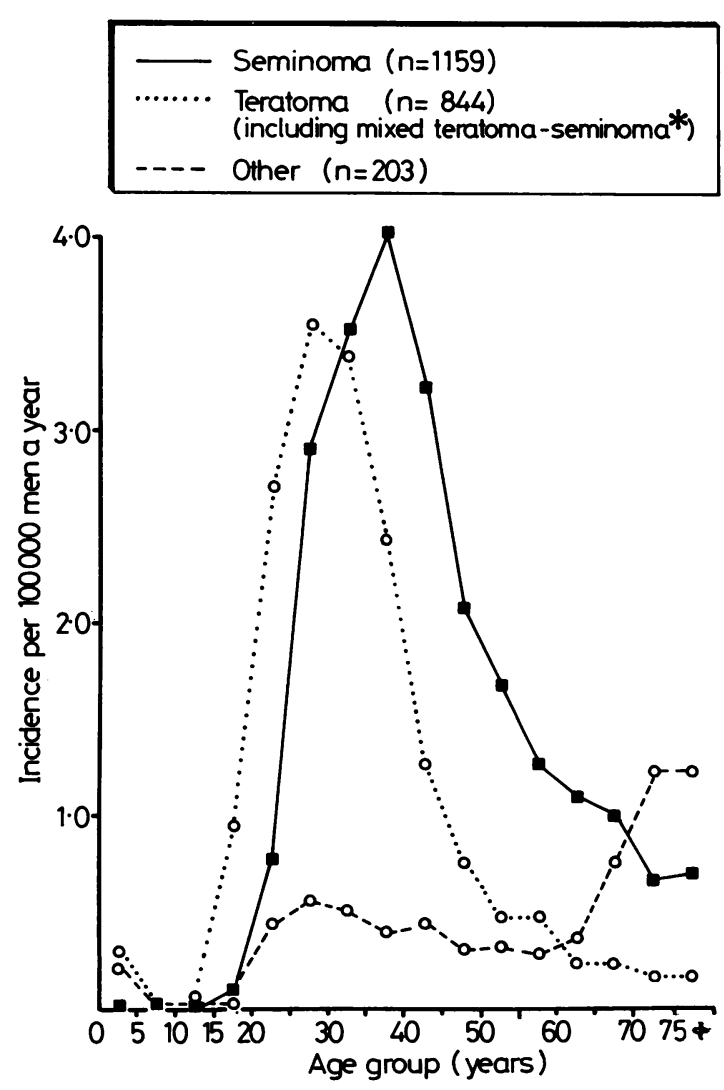

Age specific incidence rates of testicular cancer, by histology, 1958-77, South Thames Cancer Registry regions not including 42 testicular cancers of unknown histology, and two seminomas of unknown age, incident during the study period.

*Teratoma and mixed teratoma-seminoma were coded as one in the registry files and could not therefore be analysed separately.

tronic workers, and XXI clerical workers.

These occupations had a risk twice or more that in the lowest risk occupations, and in general they were also at high risk of subdivisions of the tumour by age and histology. For two other occupations there was notably high risk of particular subgroups of testicular cancer, although based on small numbers of cases: risk was high for I farmers, foresters, and fishermen aged 45-74, and for XIII paper and printing workers aged 45-74 and for teratoma.

Testicular cancer was commonest in higher social classes (table 2), for ages 15-74 combined and for each age group within this span. Risk for social class II compared with other classes diminished with increasing age but otherwise age did not appreciably affect the relation of risk to social class. Risk by social class did not vary notably by histology.

\section{Discussion}

The use of routine data from a cancer registry has the advantage of providing far larger numbers of cases for analysis of occupation and risk of testicular cancer than have been available in ad hoc studies. This is particularly of value for the examination of risks by histology and age. Routine data have potential disadvantages-potential lower accuracy than data obtained by interview, information available on most recent occupation not lifetime occupational history, a greater proportion of missing data than would be expected at interview; however, the similarity of most of the present results for those analyses previously undertaken to the results of previous studies using a range of different methods, discussed below, suggests that these potential difficulties were not of important effect in the present data and that potential control biases too were not of importance.

The high risks of testicular cancer found in the present data for administrators and managers, and professional and allied workers, are also found in England and Wales national registration data $^{78}$ (and OPCS unpublished data) and mortality data, ${ }^{9}$ and in other material from England $^{6}$ and the United States, ${ }^{245}$ and are consonant with the high social class of these occupations. The high risk of testicular cancer overall in adults of high socioeconomic status or education has been found in the present study and most, ${ }^{2-582029}$ but not all, ${ }^{17}$ previous studies, and has been evident since 1921 in England and Wales mortality data. ${ }^{3}$ Published histology specific data on socioeconomic or educational status gradients of risk of testicular cancer have been inconsistent: two studies have found a gradient for seminoma but not clearly for non-seminoma histologies ${ }^{30}{ }^{31}$ whereas Coldman et al found no gradient for seminoma,$^{32}$ and Ross et al found a steeper gradient for embryonal carcinoma than for seminoma. ${ }^{2}$ The present larger study suggests that the social class gradient is not limited to a single histological type of testicular cancer.

In mortality data for England and Wales the social class gradient for testicular cancer has been found generally greater at the young adult peak of the disease than at older ages ${ }^{3}$ but this was not clearly the case in the present material. Mortality data unlike incidence, however, may be affected by class differences in case fatality. Also, mortality data are potentially affected by a coding artefact of little effect for incidence: lymphomas of the testis, which are a relatively common histology at older but not younger ages, are coded in the International Classification of Diseases ${ }^{25}$ to lymphoma not to testicular cancer if the histology is 
Table 1 Age adjusted odds ratios for testicular cancer by occupation order, compared with order $X X V$-professional, technical workers, and artists

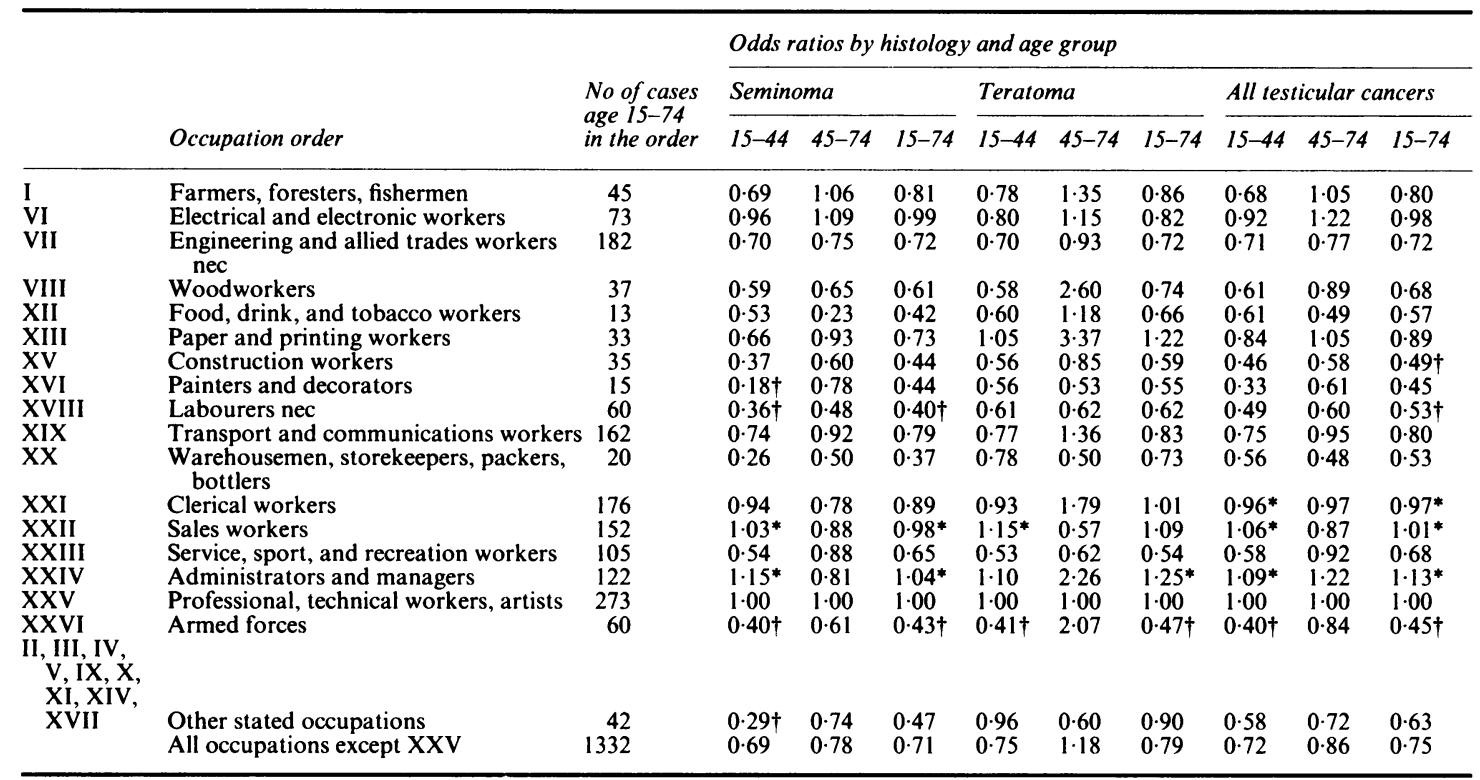

*The $95 \%$ confidence limits for this odds ratio are entirely above the point estimate of the relative risk for the aggregate of all occupations except $\mathrm{XXV}$ for the same age and histology category.

†The $95 \%$ confidence limits for this odds ratio are entirely below the point estimate of the relative risk for the aggregate of all occupations except $\mathrm{XXV}$ for the same age and histology category.

stated but are coded to testicular cancer if the histology is not stated; thus in mortality data, where histology is frequently not stated, appreciable numbers of lymphomas of the testis, the proportion varying by age, are likely to have been coded under the rubric testicular cancer, whereas the present incidence data included few testicular cancers that were of unknown histology and therefore potentially lymphomas.

Sales workers and clerical workers were at high risk of testicular cancer in the present study and in most England and Wales data sets ${ }^{7-9}$ (and OPCS unpublished data). They share with administrators and professional workers that they often work in an indoor non-industrial environment and, with exceptions mainly among sales workers, usually work seated. Their social class is somewhat lower than that of professional and allied workers (who are largely I \& II) and administrators and managers (who are entirely II); in $1971,90 \%$ of clerical workers were of social

Table 2 Age adjusted odds ratios for testicular cancer by social class

\begin{tabular}{|c|c|c|c|c|c|c|c|c|c|c|c|c|c|c|c|}
\hline \multirow[b]{2}{*}{ Age group } & \multicolumn{5}{|c|}{ All testicular cancers } & \multicolumn{5}{|c|}{ Teratoma } & \multicolumn{5}{|c|}{ Seminoma } \\
\hline & $I$ & II & $I I I$ & $I V$ & $V$ & $I$ & $I I$ & $I I I$ & $I V$ & $V$ & $I$ & $I I$ & $I I I$ & $I V$ & $V$ \\
\hline $\begin{array}{l}15-24 \\
25-34 \\
35-44 \\
45-54 \\
55-64 \\
65-74\end{array}$ & $\begin{array}{l}1.00 \\
1.00 \\
1.00 \\
1.00 \\
1.00 \\
1.00\end{array}$ & $\begin{array}{l}1.36 \\
1.29 \\
1.35 \\
0.98 \\
0.99 \\
0.64\end{array}$ & $\begin{array}{l}0.95 \\
1.02 \\
0.95 \\
0.91 \\
1.08 \\
0.63\end{array}$ & $\begin{array}{l}0.47 \\
0.72 \\
0.59 \\
0.70 \\
1.14 \\
0.43\end{array}$ & $\left.\begin{array}{l}0.67 \\
0.68 \\
0.44^{*} \\
0.53 \\
0.68 \\
0.48\end{array}\right\}$ & $\left\{\begin{array}{l}1.00 \\
1.00\end{array}\right.$ & $\begin{array}{l}1.44 \\
0.88\end{array}$ & $\begin{array}{l}1.09 \\
1.09\end{array}$ & $\begin{array}{l}0.79 \\
0.56\end{array}$ & $\begin{array}{l}0.65 \\
0.45\end{array}$ & $\begin{array}{l}1.00 \\
1.00\end{array}$ & $\begin{array}{l}1.25 \\
0.74\end{array}$ & $\begin{array}{l}0.92 \\
0.76\end{array}$ & $\begin{array}{l}0.51 \\
0.69\end{array}$ & $0.48^{*}$ \\
\hline $15-74$ & $1 \cdot 00$ & $1 \cdot 23$ & 0.97 & 0.67 & $0 \cdot 58^{*}$ & $1 \cdot 00$ & $1 \cdot 37$ & $1 \cdot 09$ & $0 \cdot 76$ & 0.63 & $1 \cdot 00$ & $1 \cdot 11$ & $0 \cdot 87$ & 0.56 & $0.46^{*}$ \\
\hline $\begin{array}{l}\text { No of } \\
\text { cases } \\
\text { age 15-74 }\end{array}$ & 124 & 345 & 827 & 159 & 78 & 45 & 130 & 343 & 57 & 29 & 73 & 186 & 425 & 84 & 37 \\
\hline
\end{tabular}

*Linear trend in risk by social class significant at $p<0.05$. 
class IIIN, and sales workers were mainly II (47\%) and IIIN (44\%) (OPCS unpublished data).

Men in the armed forces, who had raised observed to expected ratios for testicular cancer in some previous routine data sets, ${ }^{15}$ were not at high risk in the present data. This occupation, however, is one where biases are particularly likely to occur in routine data sources because of tendencies to early retirement from the occupation and for the occupation to be reported even when it was not the last job held. ${ }^{9}$

Three mainly manual occupations-farmers, foresters, and fishermen ( $57 \%$ social class IV, $40 \%$ II (OPCS unpublished data)), electrical and electronic workers (97\% IIIM) and paper and printing workers (over $99 \%$ IIIM)-were at high risk of testicular cancer at some or all ages, based on moderate or small numbers in the present data but also on examination of large numbers of cases in all ages England and Wales data. In the available registration data for England and Wales (from 1966 to 81$)^{78}$ (and OPCS unpublished data) there were PRRS greater than 100 for farmers, foresters, and fishermen (largely farmers, less than $5 \%$ are foresters and fishermen (OPCS unpublished data)) in all but two years, electrical and electronic workers in all but one year, and paper and printing workers in all years. The raised PRRs for paper and printing workers, which do not appear to have been noted previously, were particularly striking: in all but two years the PRR was greater than 150. In less extensive national mortality data ${ }^{9}$ SMRs were greater than 100 for farmers, foresters, and fishermen but not the other two occupation orders.

There is some evidence of raised risk for each of these three occupations in data from other sources. Farmers or subgroups of farmers have been found at high risk of testicular cancer in several previous studies $^{410-14}$ although not in all $^{33-35}$; differences in the type of farming in different studies may have contributed to the differences in results. In two United States data sources printing workers and electricians had raised risk but based on very small numbers. ${ }^{113} \mathrm{~A}$ non-significant excess of testicular cancer has been noted in a cohort of power station operators ${ }^{36}$ and printing workers were at raised risk in a case-control study ${ }^{32}$ restricted to seminoma (and therefore likely to include many older men). Printing workers have in common with professional and office workers, who are also at high risk of testicular cancer, exposure to printing ink.

The raised risk of testicular cancer for farmers, electrical workers, and paper and printing workers compared with their social class suggests that possible occupational risk factors for these groups may be worth further investigation. These occupations had another feature in common in the present data, which although based on small numbers here and thus not of substantial weight as evidence, is suggestive of a direction for future investigation. Each had particularly high risk at older ages. If there are occupational causes of testicular cancer one might expect them to manifest particularly at older ages for two reasons. Firstly, many of the patients with testicular cancer at the young age peak of the disease have been in employment for few if any years. Secondly, the peak of testicular cancer incidence in young adults is not the age distribution which would most obviously be expected from an occupational cause (since men usually continue working until age 60 or 65 ), whereas the age distribution in older men (rising in incidence with age) is compatible with a response to chronic cumulative exposure to a carcinogen-for instance, occupational.

For several occupations discussed in this study there is evidence in the present and other material for an association with testicular cancer. It is not yet clear, however, to what extent if at all this reflects possible occupational aetiological behaviours or exposures, or behaviours or exposures outside work associated with particular occupations. It would be of value in future person based studies of testicular cancer aetiology to include questions about exposures and behaviours related to these occupations.

We thank Dr M R Alderson for helpful comments on a previous version of this paper and Miss D Alexander for typing.

\section{References}

1 Anonymous. An epidemic of testicular cancer? Lancet 1968;ii: $164-5$.

2 Ross RK, McCurtis JW, Henderson BE, Menck HR, Mack TM, Martin SP. Descriptive epidemiology of testicular and prostatic cancer in Los Angeles. Br J Cancer 1979;39:284-92.

3 Davies JM. Testicular cancer in England and Wales: some epidemiological aspects. Lancet $1981 ; \mathrm{i}: 928-32$.

4 Graham S, Gibson RW. Social epidemiology of cancer of the testis. Cancer 1972;29:1242-9.

5 Mustacchi P, Millmore D. Racial and occupational variations in cancer of the testis: San Francisco, 1956-65.J Natl Cancer Inst 1976;56:717-20.

6 Coggon D, Pannett B, Osmond C, Acheson ED. A survey of cancer and occupation in young and middle aged men. II Nonrespiratory cancers. $\mathrm{Br} J$ Ind $\mathrm{Med}$ 1986;43:381-6.

7 Office of Population Censuses and Surveys. The Registrar General's statistical review of England and Wales for the years 196870. Supplement on cancer. London: HMSO, 1975.

8 Office of Population Censuses and Surveys. Cancer statistics. registrations. England and Wales, 1971-1981. (Series MB1 Nos 1, 2, 4, 5, 7, 8, 10, 11, 12, 13.) London: HMSO, 1979, 1979, 1980, $1981,1981,1982,1983,1983,1983,1985$.

9 Office of Population Censuses and Surveys. The Registrar General's decennial supplement for England and Wales. 1961, 1970 72. Occupational mortality. London: HMSO, 1971, 1978.

10 Williams RR, Stegens NL, Goldsmith JR. Associations of cancer site and type with occupation and industry from the third national cancer survey interview. J Natl Cancer Inst 1977;59: $1147-85$. 
11 Houten L, Bross IDJ, Viadana E. A retrospective survey of cancer in relation to occupation. (NIOSH research report. DHEW (NIOSH) publ No 77-178.) Cincinatti: National Institute for Occupational Safety and Health, 1977.

12 Milham S Jr. Occupational mortality in Washington State 1950 1979. (DHHS (NIOSH) publ No 83-116.) Cincinatti: US Department of Health and Human Services. Public Health Service. Centers for Disease Control. National Institute for Occupational Safety and Health, Division of Surveillance, Hazard Evaluations and Field Studies, 1983.

13 Mills PK, Newell GR, Johnson DE. Testicular cancer associated with employment in agriculture and oil and natural gas extraction. Lancet $1984 ;$; $207-10$

14 McDowall M, Balarajan R. Testicular cancer and employment in agriculture. Lancet 1984; i:510-1.

15 Dubrow R, Wegman DH. Setting priorities for occupational cancer research and control: synthesis of the results of occupational disease surveillance studies. $J$ Natl Cancer Inst 1983;71:1123-42.

16 Swerdlow AJ. Recent findings in the epidemiology of testicular cancer. In: Jones WG, Milford Ward A, Anderson CK, eds. Germ cell tumours II. Advances in the biosciences. Vol 55. Oxford: Pergamon, 1986:101-7.

17 Grumet RF, MacMahon B. Trends in mortality from neoplasms of the testis. Cancer 1958;11:790-7.

18 Petersen GR, Lee JAH. Secular trends of malignant tumors of the testis in white men. J Natl Cancer Inst 1972;49:339-54.

19 Swerdlow AJ, Huttly SRA, Smith PG. Testicular cancer and antecedent diseases. Br J Cancer 1987;55:97-103.

20 Graham S, Gibson R, West D, Swanson M, Burnett W, Dayal H. Epidemiology of cancer of the testis in upstate New York. $J$ Natl Cancer Inst 1977;58:1255-61.

21 Waterhouse J, Muir C, Correa P, Powell J, eds. Cancer incidence in five continents. Vol III. Lyon: International Agency for Research on Cancer, 1976.

22 Waterhouse J, Muir C, Shanmugaratnam K, Powell J, eds. Cancer incidence in five continents. Vol IV. Lyon: International Agency for Research on Cancer, 1982

23 General Register Office/Office of Population Censuses and Surveys. Classification of occupations, 1960, 1970. London: HMSO, 1960, 1970.

24 Miettinen OS, Wang J-D. An alternative to the proportionate mortality ratio. Am J Epidemiol 1981;114:144-8.

25 World Health Organisation. Manual of the international statistical classification of diseases, injuries and causes of death. 6th, 7th, 8th, 9th revs. Geneva: World Health Organisation, 1948, 1957, $1967,1978$.

26 Mantel N, Haenszel W. Statistical aspects of the analysis of data from retrospective studies of disease. J Natl Cancer Inst 1959:22:719-48

27 Mantel N. Chi-square tests with one degree of freedom; extensions of the Mantel-Haenszel procedure. Journal of the American Statistical Association 1963;58:690-700.

28 Breslow NE, Day NE. Statistical methods in cancer research. Vol 1. The analysis of case-control studies. (IARC sci publ No 32.) Lyon: International Agency for Research on Cancer, 1980.

29 Depue RH, Pike MC, Henderson BE. Estrogen exposure during gestation and risk of testicular cancer. $J$ Natl Cancer Inst 1983;71:1151-5.

30 Morrison AS. Some social and medical characteristics of army men with testicular cancer. Am J Epidemiol 1976;104:511-6.

31 Coldman AJ, Elwood JM, Gallagher RP. Sports activities and risk of testicular cancer. Br J Cancer 1982;46:749-56.

32 Nethersell ABW, Sikora $\mathrm{K}$. Testicular cancer and social class in East Anglia. Br J Cancer 1984;50:537-40.

33 Wiklund K. Swedish agricultural workers. A group with a decreased risk of cancer. Cancer 1983;51:566-8.

34 Brown LM, Pottern LM. Testicular cancer and farming. Lancet 1984; i: 1356

35 Jensen OM, Olsen $\mathrm{JH}$, Østerlind A. Testis cancer risk among farmers in Denmark. Lancet 1984;i:794.

36 Törnqvist S, Norell S, Ahlbom A, Knave B. Cancer in the electric power industry. Br J Ind Med 1986;43:212-3. 